\title{
Article \\ Chronological Gene Expression of Human Gingival Fibroblasts with Low Reactive Level Laser (LLL) Irradiation
}

\author{
Yuki Wada ${ }^{1} \mathbb{D}_{\text {, Asami Suzuki }}{ }^{2, *}$, Hitomi Ishiguro ${ }^{1,3}$, Etsuko Murakashi $^{1}$ and Yukihiro Numabe ${ }^{1,3}$ \\ 1 Department of Periodontology, School of Life Dentistry at Tokyo, The Nippon Dental University, \\ 1-9-20 Fujimi, Chiyoda-ku, Tokyo 102-8159, Japan; y-wada_d2117015@tky.ndu.ac.jp (Y.W.); \\ hitomi-i@tky.ndu.ac.jp (H.I.); satoetsu@tky.ndu.ac.jp (E.M.); numabe-y@tky.ndu.ac.jp (Y.N.) \\ 2 Division of General Dentistry, The Nippon Dental University Hospital, 2-3-16 Fujimi, Chiyoda-ku, \\ Tokyo 102-8158, Japan \\ 3 Dental Education Support Center, School of Life Dentistry, The Nippon Dental University, 1-9-20 Fujimi, \\ Chiyoda-ku, Tokyo 102-8159, Japan \\ * Correspondence: nduh-a-suzuki@tky.ndu.ac.jp; Tel.: +81-3-3261-5511
}

check for

updates

Citation: Wada, Y.; Suzuki, A.; Ishiguro, H.; Murakashi, E.; Numabe, Y. Chronological Gene Expression of Human Gingival Fibroblasts with Low Reactive Level Laser (LLL) Irradiation. J. Clin. Med. 2021, 10, 1952. https://doi.org/10.3390/ jcm10091952

Academic Editors: Gianrico Spagnuolo and Yorimasa Ogata

Received: 19 April 2021

Accepted: 29 April 2021

Published: 1 May 2021

Publisher's Note: MDPI stays neutral with regard to jurisdictional claims in published maps and institutional affiliations.

Copyright: (c) 2021 by the authors. Licensee MDPI, Basel, Switzerland. This article is an open access article distributed under the terms and conditions of the Creative Commons Attribution (CC BY) license (https:// creativecommons.org/licenses/by/ $4.0 /)$.

\begin{abstract}
Though previously studies have reported that Low reactive Level Laser Therapy (LLLT) promotes wound healing, molecular level evidence was uncleared. The purpose of this study is to examine the temporal molecular processes of human immortalized gingival fibroblasts (HGF) by LLLT by the comprehensive analysis of gene expression. HGF was seeded, cultured for $24 \mathrm{~h}$, and then irradiated with a Nd: YAG laser at $0.5 \mathrm{~W}$ for $30 \mathrm{~s}$. After that, gene differential expression analysis and functional analysis were performed with DNA microarray at 1, 3, 6 and $12 \mathrm{~h}$ after the irradiation. The number of genes with up- and downregulated differentially expression genes (DEGs) compared to the nonirradiated group was large at 6 and $12 \mathrm{~h}$ after the irradiation. From the functional analysis results of DEGs, Biological Process (BP) based Gene Ontology (GO), BP 'the defense response' is considered to be an important process with DAVID. Additionally, the results of PPI analysis of DEGs involved in the defense response with STRING, we found that the upregulated DEGs such as CXCL8 and NFKB1, and the downregulated DEGs such as NFKBIA and STAT1 were correlated with multiple genes. We estimate that these genes are key genes on the defense response after LLLT.
\end{abstract}

Keywords: Low reactive Level Laser Therapy (LLLT); human gingival fibroblasts (HGF); microarray; differentially gene expression (DEGs); gene ontology; biological processes (BP); protein-protein interaction (PPI)

\section{Introduction}

Periodontal disease is a chronic multifactorial inflammatory disease caused by genetic, immune, environmental, microbial factors and lifestyles, with anaerobic bacteria in the oral cavity as the main causative organism. Periodontal disease is generally treated with nonsurgical therapy, that is performed with hand or power-driven instrumentation. In recent years, combination therapies with scaler and laser, or laser alone have attracted attention [1-3].

The laser therapy methods currently used for treatment of periodontal diseases can be broadly divided into two types: High reactive Level Laser Therapy (HLLT) and Low reactive Level Laser Therapy (LLLT).

HLLT is an application of laser intensity that produces an irreversible reaction (photobiological destruction reaction) beyond the cell survival region and is used for tissue incision and transpiration [4-6].

On the other hand, LLLT is a treatment that applies laser intensity to generate a reversible reaction (photobiologically active reaction) within the cell survival threshold. LLLT are expected to have anti-inflammatory effects [7-12]; pain relief [13], improvement/promotion of blood flow [14], activation of cells in tissues, wound healing by proliferation [15] and tissue regeneration without causing tissue degeneration with low-power 
laser irradiation conditions [16-18]. In recent years, the promotion of wound healing with LLLT has been one of the highlights.

Wound healing is thought to progress in the process of hemorrhagic coagulation phase, inflammatory phase, proliferative phase, reconstruction phase after injury by external stimulus. During the hemorrhagic coagulation phase, blood is coagulated by platelets, which is one of the coagulation factors, and growth factors such as platelet-derived growth factor (PDGF) and cytokines are released from the platelets. During the inflammatory phase, factors such as Nuclear Factor- $\mathrm{KB}$ (NF- $\mathrm{kB}$ ) cause infiltration of inflammatory cells such as neutrophils and macrophages. Then, the release of growth factors and cytokines such as transforming growth factor- $\beta$ (TGF- $\beta$ ) and fibroblast growth factor (FGF) is observed [19]. During the proliferative phase, it promotes the migration and proliferation of fibroblasts and keratinocytes [20]. Extracellular matrix is synthesized from fibroblasts and serves as a scaffold for cell migration and adhesion. During maturity, scar tissue formation occurs.

In the study of LLLT, TGF- $\beta 1$ is closely involved in cell differentiation, migration, and adhesion by LLLT. In addition, it is thought to be involved in a wide range of areas such as ontogeny, tissue reconstruction, wound healing, inflammation/immunity, and cancer infiltration/metastasis. It has also been reported that the expression of NF- $\mathrm{kB}$ is increased [21].

Previous studies reported that the effects of low-reaction level laser irradiation on periodontium-derived cultured cells have been mainly on cell proliferation and cell transport ability related to wound healing. However, the elucidation of the mechanism at the molecular level leading to the promotion of wound healing by laser irradiation has been insufficient. It is considered that there may be a series of processes related to various wound healing by LLLT by the approach from biological processes (BP). There are few studies on mechanism analysis at the gene level using microarrays by LLLT for HGF, and only a limited number of studies have analyzed gene expression over time [22,23]. In order to clarify the effect of laser irradiation by LLLT, it is important to analyze and consider changes in gene expression and changes in BP of differentially expression genes (DEGs) over time in order to understand the mechanism at the molecular level.

In this study, HGF was irradiated with LLLT, and gene expression fluctuations at 1, 3, 6, and $12 \mathrm{~h}$ after irradiation were analyzed using a DNA microarray. In addition, we focused on the defense response, which showed remarkable changes in gene expression over time in relation to wound healing obtained from the results of vast amounts of analytical data, and to investigate for the mechanism from the expression change genes and BP due to the photobiological effects of laser. The aim of this study was to elucidate the changes of gene expression on the wound healing, especially defense response, over time after irradiation.

\section{Materials and Methods}

\subsection{Cell Culture}

Human immortalized gingival fibroblasts (HGF; Applied Biological Material, Richmond, BC, Canada) were used, and 10\% Fetal Bovine Serum (Moregate, Bulimba, Australia), $50 \mathrm{U} / \mathrm{mL}$ Penicilin G, $50 \mu \mathrm{g} / \mathrm{mL}$ Amphotericin. The study was carried out by culturing in D-MEM/F-12 medium (Life Technologies Corporation, Grand Island, NY, USA) under $37^{\circ} \mathrm{C}$, and $5 \% \mathrm{CO}_{2}$ conditions. The HGF at the time of irradiation was in the logarithmic growth phase.

\subsection{Dental Laser Device and Laser Irradiation Stent}

A dental Nd: YAG laser: impulse dental laser (Incisive Japan Co., Ltd., Tokyo, Japan) was used as a dental laser device, and an ultrafine fiber with a diameter of $320 \mathrm{~nm}$ was used for the laser light guide tip. Stents (Gikousha, Kanagawa, Japan) were prepared to uniformly irradiate cells with laser, attached to a handpiece, and used for research. Irradiation conditions were found to be significantly different in cell proliferation curvature in previous studies, irradiation output conditions $0.5 \mathrm{~W}$ (100 mJ, 5 pps), irradiation time 
$30 \mathrm{~s}$, irradiation distance from the tip of the fiber guide to each well plate. Laser irradiation was performed with a distance of $20 \mathrm{~mm}$ to the bottom [24].

\subsection{Microarray Analysis}

Total RNA was extracted from HGF with RNeasy ${ }^{\circledR}$ Plus Micro Kit (QIAGEN, Valencia, CA, USA) before laser irradiation 1, 3, 6 and $12 \mathrm{~h}$ after irradiation on a 96-well plate. cDNA was synthesized from total RNA using the SuperScript ${ }^{\mathrm{TM}}$ VILO ${ }^{\mathrm{TM}}$ cDNA Synthesis Kit (Invitrogen, Carlsbad, CA, USA). After synthesis, the cDNA was fragmented and biotin labeled. Biotin-labeled cDNA was added to the GeneChipTM Human Gene 2.0 ST Array (Thermo Fisher Scientific Inc., Waltham, MA, USA) and hybridized with a probe (GeneChipTM Hybridization, Wash, and Stain Kit; Thermo Fisher Scientific Inc., Waltham, MA, USA). Phycoerythrin staining was performed, and the fluorescence signal was measured with a GeneChip scanner (Scanner 30007 G; Thermo Fisher Scientific Inc., Waltham, MA, USA). After normalization, Expression Gene was analyzed by SST-RMA algorithm.

\subsection{Data Analysis of Differentially Expressed Genes (DEGs)}

DEGs were extracted with Affymetrix ${ }^{\circledR}$ Expression ConsoleTM (Thermo Fisher Scientific Inc. Waltham, MA, USA). The cutoff values were fold change (FC) $\geq|1.5|$ and $p$-value $<0.05$. The nonirradiated group (control), the irradiated group (test) were defined as upregulated DEGs with significantly increased expression, and downregulated DEGs with significantly decreased expression with respect to the control group.

\subsection{Functional Analysis of Differentially Expressed Genes}

A functional analysis of DEGs was performed based on Gene Ontology (GO) with the database for annotation, visualization and integrated discovery (DAVID). Enrichment analysis on the BP was performed on the DEGs at 1,3,6, and $12 \mathrm{~h}$ after irradiation. The cutoff value was a modified Fisher exact $p$-value $<0.1$, total count $\leq 2$. The DEGs contained in the upregulated and the downregulated regions at each irradiation time were analyzed.

\subsection{Protein-Protein Interaction (PPI) of Up-or Downregulated DEGs}

We focused on the defense response which is an important response on the wound healing process. PPI analysis of up- or downregulated DEGs, which were involved in defense response and continuously observed as up- or downregulated at 6 and $12 \mathrm{~h}$, and related expression fluctuations were observed at all times after irradiation and Search Tool for the Retrieval of Interacting Genes (STRING) was performed. Furthermore, from the analysis of PPI, variation in the expression of genes correlated with other DEGs over time was analyzed.

\section{Results}

\subsection{Extraction of DEGs}

In order to compare the gene expression after laser irradiation on time course, the DEGs were extracted. DEGs were extracted under the condition that the cutoff value was FC $\geq|1.5|$ and $p$-value $<0.05$. Control and test were defined as upregulated DEGs with significantly increased expression and downregulated DEGs with significantly decreased expression with respect to the control group. At $1 \mathrm{~h}$ after the irradiation, 83 upregulated and 50 downregulated genes were extracted (Supplementary Tables S1 and S2). At $3 \mathrm{~h}$ after, 46 upregulated genes and 32 downregulated genes (Supplementary Tables S3 and S4), at $6 \mathrm{~h}$ after, 362 upregulated and 549 downregulated genes (Supplementary Tables S5 and S6) and at $12 \mathrm{~h}$ after, 253 upregulated genes and 413 downregulated were extracted (Supplementary Tables S7 and S8).

The number of DEGs was large 6 and $12 \mathrm{~h}$ after the irradiation. At $6 \mathrm{~h}$, the number of DEGs was the highest in both the upregulated gene and downregulated gene groups. 


\subsection{Functional Analysis on $G O$}

From the results of functional analysis with DAVID, the number of BP related with each DEG after the irradiation was $13 \mathrm{BP}$ on upregulated and $35 \mathrm{BP}$ on downregulated DEGs at $1 \mathrm{~h}$ after, $6 \mathrm{BP}$ on upregulated and $68 \mathrm{BP}$ on downregulated DEGs at $3 \mathrm{~h}$ after, $212 \mathrm{BP}$ on upregulated and $288 \mathrm{BP}$ on downregulated DEGs at $6 \mathrm{~h}$ after, and $84 \mathrm{BP}$ on upregulated and $425 \mathrm{BP}$ on downregulated DEGs at $12 \mathrm{~h}$ after. The number of BP was small at 1 and $3 \mathrm{~h}$, and the number of BP was large at 6 and $12 \mathrm{~h}$. Tables 1-8 show the top BPs for each irradiation time.

BPs on upregulated DEGs at $1 \mathrm{~h}$ after irradiation are, for example, GO: 0050867 positive regulation of cell activation, GO: $0050865 \sim$ regulation of cell activation (Table 1), BPs on downregulated DEGs are, for example, GO: $0032774 \sim$ RNA biosynthetic process, GO: $0007267 \sim$ cell-cell signaling (Table 2).

At $3 \mathrm{~h}$ after the irradiation, BPs on upregulated DEGs are, for example, GO: 0055085 transmembrane transport, GO: $0006820 \sim$ anion transport (Table 3), BPs on down-]regulated DEGs are, for example, GO: $0032774 \sim$ RNA biosynthetic process, GO: $0016070 \sim$ RNA metabolic process (Table 4).

At 6 h, BPs on upregulated DEGs are, for example, GO: $0008283 \sim$ cell proliferation, GO: $0007155 \sim$ cell adhesion GO: $0022610 \sim$ biological adhesion, GO: $0042127 \sim$ regulation of cell proliferation, GO: $0006952 \sim$ defense response, GO: $0060429 \sim$ epithelium development (Table 5), BP on downregulated DEGs are, for example, GO: $0034645 \sim$ cellular macromolecule biosynthetic process, GO: $0019438 \sim$ aromatic compound biosynthetic process, GO: $0006325 \sim$ chromatin organization, GO: $0007049 \sim$ cell cycle (Table 6).

At $12 \mathrm{~h}$, BPs on upregulated DEGs are, for example, GO: $0006955 \sim$ immune response, GO: $0006952 \sim$ defense response, GO: $0009605 \sim$ response to external stimulus, GO: 0048584 $\sim$ positive regulation of response to stimulus (Table 7), BPs on downregulated DEGs are, for example, GO: $0010468 \mathrm{BP}$ such as regulation of gene expression, GO: $0007155 \sim$ cell adhesion, GO: $0022610 \sim$ biological adhesion (Table 8).

Table 1. The functional analysis of the upregulated genes at $1 \mathrm{~h}$ after Low Reactive Level Laser (LLL) irradiation.

\begin{tabular}{cllc}
\hline Gene Ontology (GO) ID and Terms on Biological Process (BP) & Count & $\%$ & $p$-Value \\
\hline GO:0061024 membrane organization & 6 & 6.67 & $4.45 \times 10^{-2}$ \\
GO:0002696 positive regulation of leukocyte activation & 4 & 4.44 & $2.15 \times 10^{-2}$ \\
GO:0050867 positive regulation of cell activation & 4 & 4.44 & $2.31 \times 10^{-2}$ \\
GO:0002694 regulation of leukocyte activation & 4 & 4.44 & $6.00 \times 10^{-2}$ \\
GO:0072657 protein localization to membrane & 4 & 4.44 & $6.66 \times 10^{-2}$ \\
GO:0050865 regulation of cell activation & 4 & 4.44 & $7.06 \times 10^{-2}$ \\
GO:0008037 cell recognition & 3 & 3.33 & $3.60 \times 10^{-2}$ \\
GO:0072659 protein localization to plasma membrane & 3 & 3.33 & $5.98 \times 10^{-2}$ \\
GO:1990778 protein localization to cell periphery & 3 & 3.33 & $6.97 \times 10^{-2}$ \\
GO:0007009 plasma membrane organization & 3 & 3.33 & $9.88 \times 10^{-2}$ \\
GO:0006910 phagocytosis, recognition & 2 & 2.22 & $6.52 \times 10^{-2}$ \\
GO:2000243 positive regulation of reproductive process & 2 & 2.22 & $8.66 \times 10^{-2}$ \\
GO:0006911 phagocytosis, engulfment & 2 & 2.22 & $9.18 \times 10^{-2}$ \\
\hline
\end{tabular}

Count: genes involved in the term; percentage (\%): involved genes/total genes; $p$-value: modified Fisher exact $p$-value. 
Table 2. The functional analysis of the downregulated genes at $1 \mathrm{~h}$ after LLL irradiation.

\begin{tabular}{|c|c|c|c|}
\hline Gene Ontology (GO) ID and Terms on Biological Process (BP) & Count & $\%$ & $p$-Value \\
\hline GO:0032774 RNA biosynthetic process & 10 & 18.52 & $1.27 \times 10^{-2}$ \\
\hline GO:0034654 nucleobase-containing compound biosynthetic process & 10 & 18.52 & $2.59 \times 10^{-2}$ \\
\hline GO:0018130 heterocycle biosynthetic process & 10 & 18.52 & $2.79 \times 10^{-2}$ \\
\hline GO:0019438 aromatic compound biosynthetic process & 10 & 18.52 & $2.85 \times 10^{-2}$ \\
\hline GO:0016070 RNA metabolic process & 10 & 18.52 & $3.87 \times 10^{-2}$ \\
\hline GO:0034645 cellular macromolecule biosynthetic process & 10 & 18.52 & $6.07 \times 10^{-2}$ \\
\hline GO:0010467 gene expression & 10 & 18.52 & $8.40 \times 10^{-2}$ \\
\hline GO:0007267 cell-cell signaling & 5 & 9.26 & $7.48 \times 10^{-2}$ \\
\hline GO:0006614 SRP-dependent cotranslational protein targeting to membrane & 3 & 5.56 & $4.74 \times 10^{-3}$ \\
\hline GO:0006613 cotranslational protein targeting to membrane & 3 & 5.56 & $5.44 \times 10^{-3}$ \\
\hline GO:0045047 protein targeting to ER & 3 & 5.56 & $5.54 \times 10^{-3}$ \\
\hline GO:0072599 establishment of protein localization to endoplasmic reticulum & 3 & 5.56 & $5.96 \times 10^{-3}$ \\
\hline GO:0000184 nuclear-transcribed mRNA catabolic process, nonsense-mediated decay & 3 & 5.56 & $7.67 \times 10^{-3}$ \\
\hline GO:0070972 protein localization to endoplasmic reticulum & 3 & 5.56 & $8.28 \times 10^{-3}$ \\
\hline GO:0019083 viral transcription & 3 & 5.56 & $1.60 \times 10^{-2}$ \\
\hline GO:0006413 translational initiation & 3 & 5.56 & $1.74 \times 10^{-2}$ \\
\hline GO:0006612 protein targeting to membrane & 3 & 5.56 & $1.76 \times 10^{-2}$ \\
\hline GO:0019080 viral gene expression & 3 & 5.56 & $1.79 \times 10^{-2}$ \\
\hline GO:0000956 nuclear-transcribed mRNA catabolic process & 3 & 5.56 & $2.05 \times 10^{-2}$ \\
\hline GO:0044033 multiorganism metabolic process & 3 & 5.56 & $2.20 \times 10^{-2}$ \\
\hline GO:0006402 mRNA catabolic process & 3 & 5.56 & $2.33 \times 10^{-2}$ \\
\hline GO:0006401 RNA catabolic process & 3 & 5.56 & $2.91 \times 10^{-2}$ \\
\hline GO:0006364 rRNA processing & 3 & 5.56 & $3.36 \times 10^{-2}$ \\
\hline GO:0016072 rRNA metabolic process & 3 & 5.56 & $3.52 \times 10^{-2}$ \\
\hline GO:0042254 ribosome biogenesis & 3 & 5.56 & $5.00 \times 10^{-2}$ \\
\hline GO:0090150 establishment of protein localization to membrane & 3 & 5.56 & $5.91 \times 10^{-2}$ \\
\hline GO:0034655 nucleobase-containing compound catabolic process & 3 & 5.56 & $6.25 \times 10^{-2}$ \\
\hline GO:0034470 ncRNA processing & 3 & 5.56 & $7.17 \times 10^{-2}$ \\
\hline GO:0046700 heterocycle catabolic process & 3 & 5.56 & $7.17 \times 10^{-2}$ \\
\hline GO:0044270 cellular nitrogen compound catabolic process & 3 & 5.56 & $7.38 \times 10^{-2}$ \\
\hline GO:0019439 aromatic compound catabolic process & 3 & 5.56 & $7.54 \times 10^{-2}$ \\
\hline GO:1901361 organic cyclic compound catabolic process & 3 & 5.56 & $8.23 \times 10^{-2}$ \\
\hline GO:0019058 viral life cycle & 3 & 5.56 & $8.55 \times 10^{-2}$ \\
\hline GO:0022613 ribonucleoprotein complex biogenesis & 3 & 5.56 & $9.37 \times 10^{-2}$ \\
\hline GO:0072657 protein localization to membrane & 3 & 5.56 & $9.67 \times 10^{-2}$ \\
\hline
\end{tabular}

Count: genes involved in the term; percentage (\%): involved genes/total genes; $p$-value: modified Fisher exact $p$-value.

Table 3. The functional analysis of the upregulated genes at $3 \mathrm{~h}$ after LLL irradiation.

\begin{tabular}{cclc}
\hline Gene Ontology (GO) ID and Terms on Biological Process (BP) & Count & $\%$ & $p$-Value \\
\hline GO:0055085 transmembrane transport & 5 & 0.30 & $5.87 \times 10^{-2}$ \\
GO:1901615 organic hydroxy compound metabolic process & 3 & 0.18 & $7.85 \times 10^{-2}$ \\
GO:0006820 anion transport & 3 & 0.18 & $9.85 \times 10^{-2}$ \\
GO:0051180 vitamin transport & 2 & 0.12 & $3.81 \times 10^{-2}$ \\
GO:0006767 water-soluble vitamin metabolic process & 2 & 0.12 & $9.58 \times 10^{-2}$ \\
\hline
\end{tabular}

Count: genes involved in the term; percentage (\%): involved genes/total genes; $p$-value: modified Fisher exact $p$-value. 
Table 4. The functional analysis of the downregulated genes at $3 \mathrm{~h}$ after LLL irradiation.

\begin{tabular}{|c|c|c|c|}
\hline Gene Ontology (GO) ID and Terms on Biological Process (BP) & Count & $\%$ & $p$-Value \\
\hline GO:0032774 RNA biosynthetic process & 6 & 15.79 & $3.8 \times 10^{-2}$ \\
\hline GO:0034654 nucleobase-containing compound biosynthetic process & 6 & 15.79 & $5.85 \times 10^{-2}$ \\
\hline GO:0018130 heterocycle biosynthetic process & 6 & 15.79 & $6.14 \times 10^{-2}$ \\
\hline GO:0019438 aromatic compound biosynthetic process & 6 & 15.79 & $6.21 \times 10^{-2}$ \\
\hline GO:0016070 RNA metabolic process & 6 & 15.79 & $7.52 \times 10^{-2}$ \\
\hline GO:0044085 cellular component biogenesis & 5 & 13.16 & $5.62 \times 10^{-2}$ \\
\hline GO:0006614 SRP-dependent cotranslational protein targeting to membrane & 4 & 10.53 & $1.52 \times 10^{-5}$ \\
\hline GO:0006613 cotranslational protein targeting to membrane & 4 & 10.53 & $1.88 \times 10^{-5}$ \\
\hline GO:0045047 protein targeting to ER & 4 & 10.53 & $1.94 \times 10^{-5}$ \\
\hline GO:0072599 establishment of protein localization to endoplasmic reticulum & 4 & 10.53 & $2.17 \times 10^{-5}$ \\
\hline GO:0000184 nuclear-transcribed mRNA catabolic process, nonsense-mediated decay & 4 & 10.53 & $3.20 \times 10^{-5}$ \\
\hline GO:0070972 protein localization to endoplasmic reticulum & 4 & 10.53 & $3.60 \times 10^{-5}$ \\
\hline GO:0019083 viral transcription & 4 & 10.53 & $1.01 \times 10^{-4}$ \\
\hline GO:0006413 translational initiation & 4 & 10.53 & $1.15 \times 10^{-4}$ \\
\hline GO:0006612 protein targeting to membrane & 4 & 10.53 & $1.17 \times 10^{-4}$ \\
\hline GO:0019080 viral gene expression & 4 & 10.53 & $1.20 \times 10^{-4}$ \\
\hline GO:0000956 nuclear-transcribed mRNA catabolic process & 4 & 10.53 & $1.48 \times 10^{-4}$ \\
\hline GO:0044033 multiorganism metabolic process & 4 & 10.53 & $1.66 \times 10^{-4}$ \\
\hline GO:0006402 mRNA catabolic process & 4 & 10.53 & $1.83 \times 10^{-4}$ \\
\hline GO:0006401 RNA catabolic process & 4 & 10.53 & $2.60 \times 10^{-4}$ \\
\hline GO:0006364 rRNA processing & 4 & 10.53 & $3.26 \times 10^{-4}$ \\
\hline GO:0016072 rRNA metabolic process & 4 & 10.53 & $3.51 \times 10^{-4}$ \\
\hline GO:0042254 ribosome biogenesis & 4 & 10.53 & $6.20 \times 10^{-4}$ \\
\hline GO:0090150 establishment of protein localization to membrane & 4 & 10.53 & $8.15 \times 10^{-4}$ \\
\hline GO:0034655 nucleobase-containing compound catabolic process & 4 & 10.53 & $8.94 \times 10^{-4}$ \\
\hline GO:0034470 ncRNA processing & 4 & 10.53 & $1.12 \times 10^{-3}$ \\
\hline GO:0046700 heterocycle catabolic process & 4 & 10.53 & $1.12 \times 10^{-3}$ \\
\hline GO:0044270 cellular nitrogen compound catabolic process & 4 & 10.53 & $1.18 \times 10^{-3}$ \\
\hline GO:0019439 aromatic compound catabolic process & 4 & 10.53 & $1.22 \times 10^{-3}$ \\
\hline GO:1901361 organic cyclic compound catabolic process & 4 & 10.53 & $1.41 \times 10^{-3}$ \\
\hline GO:0019058 viral life cycle & 4 & 10.53 & $1.51 \times 10^{-3}$ \\
\hline GO:0022613 ribonucleoprotein complex biogenesis & 4 & 10.53 & $1.76 \times 10^{-3}$ \\
\hline GO:0072657 protein localization to membrane & 4 & 10.53 & $1.85 \times 10^{-3}$ \\
\hline GO:0034660 ncRNA metabolic process & 4 & 10.53 & $2.87 \times 10^{-3}$ \\
\hline GO:0006412 translation & 4 & 10.53 & $4.01 \times 10^{-3}$ \\
\hline GO:0072594 establishment of protein localization to organelle & 4 & 10.53 & $4.47 \times 10^{-3}$ \\
\hline GO:0043043 peptide biosynthetic process & 4 & 10.53 & $4.49 \times 10^{-3}$ \\
\hline GO:0016071 mRNA metabolic process & 4 & 10.53 & $4.58 \times 10^{-3}$ \\
\hline GO:1902582 single-organism intracellular transport & 4 & 10.53 & $5.04 \times 10^{-3}$ \\
\hline GO:0006605 protein targeting & 4 & 10.53 & $5.16 \times 10^{-3}$ \\
\hline GO:0043604 amide biosynthetic process & 4 & 10.53 & $5.92 \times 10^{-3}$ \\
\hline GO:0006518 peptide metabolic process & 4 & 10.53 & $7.94 \times 10^{-3}$ \\
\hline GO:0044802 single-organism membrane organization & 4 & 10.53 & $9.30 \times 10^{-3}$ \\
\hline GO:0033365 protein localization to organelle & 4 & 10.53 & $1.04 \times 10^{-2}$ \\
\hline GO:0006396 RNA processing & 4 & 10.53 & $1.07 \times 10^{-2}$ \\
\hline GO:0016032 viral process & 4 & 10.53 & $1.26 \times 10^{-2}$ \\
\hline GO:0044764 multiorganism cellular process & 4 & 10.53 & $1.28 \times 10^{-2}$ \\
\hline GO:0044265 cellular macromolecule catabolic process & 4 & 10.53 & $1.29 \times 10^{-2}$ \\
\hline GO:0043603 cellular amide metabolic process & 4 & 10.53 & $1.36 \times 10^{-2}$ \\
\hline GO:0044403 symbiosis, encompassing mutualism through parasitism & 4 & 10.53 & $1.37 \times 10^{-2}$ \\
\hline
\end{tabular}

Count: genes involved in the term; percentage (\%): involved genes/total genes; $p$-value: modified Fisher exact $p$-value. 
Table 5. The functional analysis of the upregulated genes at $6 \mathrm{~h}$ after LLL irradiation.

\begin{tabular}{|c|c|c|c|}
\hline Gene Ontology (GO) ID and Terms on Biological Process (BP) & Count & $\%$ & $p$-Value \\
\hline GO:0034645 cellular macromolecule biosynthetic process & 72 & 19.20 & $4.50 \times 10^{-3}$ \\
\hline GO:0010467 gene expression & 67 & 17.87 & $9.63 \times 10^{-2}$ \\
\hline GO:0016070 RNA metabolic process & 65 & 17.33 & $1.49 \times 10^{-2}$ \\
\hline GO:0010468 regulation of gene expression & 64 & 17.07 & $4.90 \times 10^{-3}$ \\
\hline GO:0051171 regulation of nitrogen compound metabolic process & 64 & 17.07 & $6.75 \times 10^{-3}$ \\
\hline GO:0019219 regulation of nucleobase-containing compound metabolic process & 61 & 16.27 & $5.24 \times 10^{-3}$ \\
\hline GO:0010556 regulation of macromolecule biosynthetic process & 60 & 16.00 & $8.42 \times 10^{-3}$ \\
\hline GO:2000112 regulation of cellular macromolecule biosynthetic process & 59 & 15.73 & $7.09 \times 10^{-3}$ \\
\hline GO:0034654 nucleobase-containing compound biosynthetic process & 59 & 15.73 & $4.02 \times 10^{-2}$ \\
\hline GO:0018130 heterocycle biosynthetic process & 59 & 15.73 & $4.99 \times 10^{-2}$ \\
\hline GO:0019438 aromatic compound biosynthetic process & 59 & 15.73 & $5.24 \times 10^{-2}$ \\
\hline GO:0051252 regulation of RNA metabolic process & 58 & 15.47 & $3.04 \times 10^{-3}$ \\
\hline GO:0097659 nucleic acid-templated transcription & 57 & 15.20 & $5.26 \times 10^{-3}$ \\
\hline GO:0032774 RNA biosynthetic process & 57 & 15.20 & $1.10 \times 10^{-2}$ \\
\hline GO:0006355 regulation of transcription, DNA-templated & 54 & 14.40 & $8.34 \times 10^{-3}$ \\
\hline GO:1903506 regulation of nucleic acid-templated transcription & 54 & 14.40 & $9.42 \times 10^{-3}$ \\
\hline GO:2001141 regulation of RNA biosynthetic process & 54 & 14.40 & $1.04 \times 10^{-2}$ \\
\hline GO:0006351 transcription, DNA-templated & 53 & 14.13 & $1.32 \times 10^{-2}$ \\
\hline GO:0010646 regulation of cell communication & 47 & 12.53 & $7.96 \times 10^{-3}$ \\
\hline GO:0023051 regulation of signaling & 47 & 12.53 & $1.07 \times 10^{-2}$ \\
\hline GO:0009893 positive regulation of metabolic process & 46 & 12.27 & $1.53 \times 10^{-2}$ \\
\hline GO:0010604 positive regulation of macromolecule metabolic process & 43 & 11.47 & $2.02 \times 10^{-2}$ \\
\hline GO:0009966 regulation of signal transduction & 42 & 11.20 & $1.56 \times 10^{-2}$ \\
\hline GO:0009892 negative regulation of metabolic process & 40 & 10.67 & $1.19 \times 10^{-2}$ \\
\hline GO:0007166 cell surface receptor signaling pathway & 40 & 10.67 & $2.78 \times 10^{-2}$ \\
\hline GO:0031325 positive regulation of cellular metabolic process & 40 & 10.67 & $6.31 \times 10^{-2}$ \\
\hline GO:0010605 negative regulation of macromolecule metabolic process & 39 & 10.40 & $5.48 \times 10^{-3}$ \\
\hline GO:0031324 negative regulation of cellular metabolic process & 37 & 9.87 & $1.76 \times 10^{-2}$ \\
\hline GO:0006366 transcription from RNA polymerase II promoter & 35 & 9.33 & $1.02 \times 10^{-3}$ \\
\hline GO:0006357 regulation of transcription from RNA polymerase II promoter & 35 & 9.33 & $1.17 \times 10^{-3}$ \\
\hline GO:0010628 positive regulation of gene expression & 33 & 8.80 & $1.19 \times 10^{-3}$ \\
\hline GO:0071310 cellular response to organic substance & 32 & 8.53 & $6.76 \times 10^{-2}$ \\
\hline GO:0051173 positive regulation of nitrogen compound metabolic process & 31 & 8.27 & $8.31 \times 10^{-3}$ \\
\hline GO:0048584 positive regulation of response to stimulus & 31 & 8.27 & $4.62 \times 10^{-2}$ \\
\hline GO:0009891 positive regulation of biosynthetic process & 30 & 8.00 & $1.39 \times 10^{-2}$ \\
\hline GO:0031328 positive regulation of cellular biosynthetic process & 29 & 7.73 & $1.93 \times 10^{-2}$ \\
\hline GO:0006468 protein phosphorylation & 29 & 7.73 & $4.20 \times 10^{-2}$ \\
\hline GO:0008283 cell proliferation & 29 & 7.73 & $4.43 \times 10^{-2}$ \\
\hline GO:0008219 cell death & 29 & 7.73 & $7.43 \times 10^{-2}$ \\
\hline GO:0010557 positive regulation of macromolecule biosynthetic process & 28 & 7.47 & $1.29 \times 10^{-2}$ \\
\hline GO:0045935 positive regulation of nucleobase-containing compound metabolic process & 28 & 7.47 & $2.02 \times 10^{-2}$ \\
\hline GO:0012501 programmed cell death & 28 & 7.47 & $6.56 \times 10^{-2}$ \\
\hline GO:0007155 cell adhesion & 27 & 7.20 & $4.37 \times 10^{-2}$ \\
\hline GO:0022610 biological adhesion & 27 & 7.20 & $4.53 \times 10^{-2}$ \\
\hline GO:2000026 regulation of multicellular organismal development & 27 & 7.20 & $4.97 \times 10^{-2}$ \\
\hline GO:0006915 apoptotic process & 27 & 7.20 & $5.76 \times 10^{-2}$ \\
\hline GO:0051254 positive regulation of RNA metabolic process & 26 & 6.93 & $9.98 \times 10^{-3}$ \\
\hline GO:1902531 regulation of intracellular signal transduction & 26 & 6.93 & $7.47 \times 10^{-2}$ \\
\hline GO:0048585 negative regulation of response to stimulus & 25 & 6.67 & $1.26 \times 10^{-2}$ \\
\hline GO:0009890 negative regulation of biosynthetic process & 25 & 6.67 & $3.44 \times 10^{-2}$ \\
\hline GO:0042127 regulation of cell proliferation & 25 & 6.67 & $4.68 \times 10^{-2}$ \\
\hline GO:0048646 anatomical structure formation involved in morphogenesis & 24 & 6.40 & $3.17 \times 10^{-3}$ \\
\hline GO:0010558 negative regulation of macromolecule biosynthetic process & 24 & 6.40 & $3.25 \times 10^{-2}$ \\
\hline
\end{tabular}


Table 5. Cont

\begin{tabular}{|c|c|c|c|}
\hline Gene Ontology (GO) ID and Terms on Biological Process (BP) & Count & $\%$ & $p$-Value \\
\hline GO:0031327 negative regulation of cellular biosynthetic process & 24 & 6.40 & $4.89 \times 10^{-2}$ \\
\hline GO:0010629 negative regulation of gene expression & 24 & 6.40 & $5.04 \times 10^{-2}$ \\
\hline GO:0045893 positive regulation of transcription, DNA-templated & 23 & 6.13 & $3.43 \times 10^{-2}$ \\
\hline GO:1903508 positive regulation of nucleic acid-templated transcription & 23 & 6.13 & $3.43 \times 10^{-2}$ \\
\hline GO:1902680 positive regulation of RNA biosynthetic process & 23 & 6.13 & $3.94 \times 10^{-2}$ \\
\hline GO:0002682 regulation of immune system process & 23 & 6.13 & $4.19 \times 10^{-2}$ \\
\hline GO:0006952 defense response & 23 & 6.13 & $9.61 \times 10^{-2}$ \\
\hline GO:0010648 negative regulation of cell communication & 22 & 5.87 & $1.69 \times 10^{-2}$ \\
\hline GO:0023057 negative regulation of signaling & 22 & 5.87 & $1.74 \times 10^{-2}$ \\
\hline GO:0080134 regulation of response to stress & 22 & 5.87 & $3.76 \times 10^{-2}$ \\
\hline GO:2000113 negative regulation of cellular macromolecule biosynthetic process & 22 & 5.87 & $4.90 \times 10^{-2}$ \\
\hline GO:0051240 positive regulation of multicellular organismal process & 22 & 5.87 & $9.32 \times 10^{-2}$ \\
\hline GO:0051094 positive regulation of developmental process & 21 & 5.60 & $1.41 \times 10^{-2}$ \\
\hline
\end{tabular}

Count: genes involved in the term; percentage (\%): involved genes/total genes; $p$-value: modified Fisher exact $p$-value.

Table 6. The functional analysis of the downregulated genes at $6 \mathrm{~h}$ after LLL irradiation.

\begin{tabular}{|c|c|c|c|}
\hline Gene Ontology (GO) ID and Terms on Biological Process (BP) & Count & $\%$ & $p$-Value \\
\hline GO:0034645 cellular macromolecule biosynthetic process & 158 & 0.26 & $1.20 \times 10^{-6}$ \\
\hline GO:0010467 gene expression & 147 & 0.24 & $2.91 \times 10^{-3}$ \\
\hline GO:0019438 aromatic compound biosynthetic process & 141 & 0.23 & $4.17 \times 10^{-6}$ \\
\hline GO:0018130 heterocycle biosynthetic process & 138 & 0.23 & $1.59 \times 10^{-5}$ \\
\hline GO:0034654 nucleobase-containing compound biosynthetic process & 135 & 0.22 & $3.51 \times 10^{-5}$ \\
\hline GO:0016070 RNA metabolic process & 132 & 0.22 & $2.23 \times 10^{-3}$ \\
\hline GO:0051171 regulation of nitrogen compound metabolic process & 128 & 0.21 & $1.10 \times 10^{-3}$ \\
\hline GO:0010468 regulation of gene expression & 126 & 0.21 & $1.36 \times 10^{-3}$ \\
\hline GO:0032774 RNA biosynthetic process & 121 & 0.20 & $1.21 \times 10^{-4}$ \\
\hline GO:2000112 regulation of cellular macromolecule biosynthetic process & 121 & 0.20 & $3.10 \times 10^{-4}$ \\
\hline GO:0010556 regulation of macromolecule biosynthetic process & 121 & 0.20 & $9.90 \times 10^{-4}$ \\
\hline GO:0019219 regulation of nucleobase-containing compound metabolic process & 118 & 0.20 & $2.92 \times 10^{-3}$ \\
\hline GO:0097659 nucleic acid-templated transcription & 113 & 0.19 & $8.72 \times 10^{-4}$ \\
\hline GO:0006351 transcription, DNA-templated & 109 & 0.18 & $8.23 \times 10^{-4}$ \\
\hline GO:0006355 regulation of transcription, DNA-templated & 107 & 0.18 & $1.77 \times 10^{-3}$ \\
\hline GO:1903506 regulation of nucleic acid-templated transcription & 107 & 0.18 & $2.18 \times 10^{-3}$ \\
\hline GO:2001141 regulation of RNA biosynthetic process & 107 & 0.18 & $2.60 \times 10^{-3}$ \\
\hline GO:0051252 regulation of RNA metabolic process & 107 & 0.18 & $7.16 \times 10^{-3}$ \\
\hline GO:0009892 negative regulation of metabolic process & 90 & 0.15 & $9.30 \times 10^{-6}$ \\
\hline GO:0010605 negative regulation of macromolecule metabolic process & 86 & 0.14 & $4.06 \times 10^{-6}$ \\
\hline GO:0031324 negative regulation of cellular metabolic process & 85 & 0.14 & $1.02 \times 10^{-5}$ \\
\hline GO:0044085 cellular component biogenesis & 85 & 0.14 & $1.03 \times 10^{-2}$ \\
\hline GO:0043933 macromolecular complex subunit organization & 83 & 0.14 & $1.72 \times 10^{-4}$ \\
\hline GO:0009893 positive regulation of metabolic process & 83 & 0.14 & $5.25 \times 10^{-2}$ \\
\hline GO:0010604 positive regulation of macromolecule metabolic process & 81 & 0.13 & $2.37 \times 10^{-2}$ \\
\hline GO:0022607 cellular component assembly & 79 & 0.13 & $6.13 \times 10^{-3}$ \\
\hline GO:0051276 chromosome organization & 67 & 0.11 & 7.48.E-12 \\
\hline GO:0033554 cellular response to stress & 66 & 0.11 & $6.62 \times 10^{-5}$ \\
\hline GO:0032268 regulation of cellular protein metabolic process & 65 & 0.11 & $6.56 \times 10^{-2}$ \\
\hline GO:0031327 negative regulation of cellular biosynthetic process & 63 & 0.10 & $1.62 \times 10^{-6}$ \\
\hline GO:0009890 negative regulation of biosynthetic process & 63 & 0.10 & $2.75 \times 10^{-6}$ \\
\hline GO:0051172 negative regulation of nitrogen compound metabolic process & 63 & 0.10 & $2.91 \times 10^{-6}$ \\
\hline GO:0010558 negative regulation of macromolecule biosynthetic process & 61 & 0.10 & $1.79 \times 10^{-6}$ \\
\hline GO:0010629 negative regulation of gene expression & 61 & 0.10 & $7.71 \times 10^{-6}$ \\
\hline
\end{tabular}


Table 6. Cont.

\begin{tabular}{cccc}
\hline Gene Ontology (GO) ID and Terms on Biological Process (BP) & Count & $\%$ & $p$-Value \\
\hline GO:2000113 negative regulation of cellular macromolecule biosynthetic process & 60 & 0.10 & $4.10 \times 10^{-7}$ \\
GO:0071822 protein complex subunit organization & 60 & 0.10 & $4.18 \times 10^{-4}$ \\
GO:0045934 negative regulation of nucleobase-containing compound metabolic process & 59 & 0.10 & $2.74 \times 10^{-6}$ \\
GO:0065003 macromolecular complex assembly & 59 & 0.10 & $1.21 \times 10^{-3}$ \\
GO:0006461 protein complex assembly & 56 & 0.09 & $9.86 \times 10^{-5}$ \\
GO:0070271 protein complex biogenesis & 56 & 0.09 & $1.00 \times 10^{-4}$ \\
GO:0007049 cell cycle & 56 & 0.09 & $3.16 \times 10^{-3}$ \\
GO:0006325 chromatin organization & 54 & 0.09 & $4.01 \times 10^{-13}$ \\
GO:1903507 negative regulation of nucleic acid-templated transcription & 53 & 0.09 & $2.84 \times 10^{-6}$ \\
GO:1902679 negative regulation of RNA biosynthetic process & 53 & 0.09 & $4.28 \times 10^{-6}$ \\
GO:0051253 negative regulation of RNA metabolic process & 53 & 0.09 & $1.24 \times 10^{-5}$ \\
GO:0045892 negative regulation of transcription, DNA-templated & 52 & 0.09 & $1.93 \times 10^{-6}$ \\
GO:0034622 cellular macromolecular complex assembly & 47 & 0.08 & $4.38 \times 10^{-6}$ \\
GO:0031399 regulation of protein modification process & 47 & 0.08 & $9.08 \times 10^{-2}$ \\
GO:0044248 cellular catabolic process & 46 & 0.08 & $8.76 \times 10^{-2}$ \\
GO:0022402 cell cycle process & 44 & 0.07 & $1.65 \times 10^{-2}$ \\
\hline
\end{tabular}

Count: genes involved in the term; percentage (\%): involved genes/total genes; $p$-value: modified Fisher exact $p$-value.

Table 7. The functional analysis of the upregulated genes at $12 \mathrm{~h}$ after LLL irradiation.

\begin{tabular}{|c|c|c|c|}
\hline Gene Ontology (GO) ID and Terms on Biological Process (BP) & Count & $\%$ & $p$-Value \\
\hline GO:0007166 cell surface receptor signaling pathway & 28 & 10.73 & $2.37 \times 10^{-2}$ \\
\hline GO:0006955 immune response & 24 & 9.20 & $3.39 \times 10^{-4}$ \\
\hline GO:0006952 defense response & 23 & 8.81 & $6.37 \times 10^{-4}$ \\
\hline GO:0009605 response to external stimulus & 23 & 8.81 & $2.57 \times 10^{-2}$ \\
\hline GO:0048584 positive regulation of response to stimulus & 22 & 8.43 & $3.73 \times 10^{-2}$ \\
\hline GO:0003008 system process & 21 & 8.05 & $5.96 \times 10^{-2}$ \\
\hline GO:0002682 regulation of immune system process & 19 & 7.28 & $6.30 \times 10^{-3}$ \\
\hline GO:0050776 regulation of immune response & 18 & 6.90 & $1.70 \times 10^{-4}$ \\
\hline GO:0016192 vesicle-mediated transport & 17 & 6.51 & $5.14 \times 10^{-2}$ \\
\hline GO:0045087 innate immune response & 16 & 6.13 & $6.31 \times 10^{-4}$ \\
\hline GO:0007186 G-protein coupled receptor signaling pathway & 16 & 6.13 & $2.69 \times 10^{-2}$ \\
\hline GO:0051707 response to other organism & 15 & 5.75 & $1.72 \times 10^{-3}$ \\
\hline GO:0043207 response to external biotic stimulus & 15 & 5.75 & $1.72 \times 10^{-3}$ \\
\hline GO:0009607 response to biotic stimulus & 15 & 5.75 & $2.76 \times 10^{-3}$ \\
\hline GO:0050877 neurological system process & 15 & 5.75 & $6.02 \times 10^{-2}$ \\
\hline GO:0006897 endocytosis & 14 & 5.36 & $6.77 \times 10^{-4}$ \\
\hline GO:0002252 immune effector process & 14 & 5.36 & $1.83 \times 10^{-3}$ \\
\hline GO:0001775 cell activation & 14 & 5.36 & $1.00 \times 10^{-2}$ \\
\hline GO:0002684 positive regulation of immune system process & 14 & 5.36 & $1.51 \times 10^{-2}$ \\
\hline GO:0009617 response to bacterium & 13 & 4.98 & $3.80 \times 10^{-4}$ \\
\hline GO:0050778 positive regulation of immune response & 13 & 4.98 & $2.71 \times 10^{-3}$ \\
\hline GO:0045321 leukocyte activation & 13 & 4.98 & $5.47 \times 10^{-3}$ \\
\hline GO:0051094 positive regulation of developmental process & 13 & 4.98 & $7.29 \times 10^{-2}$ \\
\hline GO:0002768 immune response-regulating cell surface receptor signaling pathway & 12 & 4.60 & $9.96 \times 10^{-5}$ \\
\hline GO:0002764 immune response-regulating signaling pathway & 12 & 4.60 & $1.12 \times 10^{-3}$ \\
\hline GO:0046649 lymphocyte activation & 12 & 4.60 & $4.91 \times 10^{-3}$ \\
\hline GO:0002449 lymphocyte mediated immunity & 11 & 4.21 & $2.83 \times 10^{-5}$ \\
\hline GO:0002443 leukocyte mediated immunity & 11 & 4.21 & $1.79 \times 10^{-4}$ \\
\hline GO:0002250 adaptive immune response & 11 & 4.21 & $6.62 \times 10^{-4}$ \\
\hline GO:0098542 defense response to other organism & 11 & 4.21 & $2.23 \times 10^{-3}$ \\
\hline GO:0042742 defense response to bacterium & 10 & 3.83 & $9.53 \times 10^{-5}$ \\
\hline $\begin{array}{l}\text { GO:0002460 adaptive immune response based on somatic recombination of immune } \\
\text { receptors built from immunoglobulin superfamily domains }\end{array}$ & 10 & 3.83 & $1.65 \times 10^{-4}$ \\
\hline
\end{tabular}


Table 7. Cont

\begin{tabular}{cccc}
\hline Gene Ontology (GO) ID and Terms on Biological Process (BP) & Count & \% & $p$-Value \\
\hline GO:0002429 immune response-activating cell surface receptor signaling pathway & 10 & 3.83 & $1.01 \times 10^{-3}$ \\
GO:0002757 immune response-activating signal transduction & 10 & 3.83 & $7.63 \times 10^{-3}$ \\
GO:0002253 activation of immune response & 10 & 3.83 & $1.40 \times 10^{-2}$ \\
GO:0016064 immunoglobulin mediated immune response & 9 & 3.45 & $2.44 \times 10^{-5}$ \\
GO:0019724 B cell mediated immunity & 9 & 3.45 & $2.66 \times 10^{-5}$ \\
GO:0042113 B cell activation & 9 & 3.45 & $3.08 \times 10^{-4}$ \\
GO:0006959 humoral immune response & 9 & 3.45 & $3.25 \times 10^{-4}$ \\
GO:0051251 positive regulation of lymphocyte activation & 9 & 3.45 & $8.51 \times 10^{-4}$ \\
GO:0002696 positive regulation of leukocyte activation & 9 & 3.45 & $1.42 \times 10^{-3}$ \\
GO:0050867 positive regulation of cell activation & 9 & 3.45 & $1.70 \times 10^{-3}$ \\
GO:0051249 regulation of lymphocyte activation & 9 & 3.45 & $7.68 \times 10^{-3}$ \\
GO:0002694 regulation of leukocyte activation & 9 & 3.45 & $1.59 \times 10^{-2}$ \\
GO:0050865 regulation of cell activation & 9 & 3.45 & $2.28 \times 10^{-2}$ \\
GO:0006958 complement activation, classical pathway & 8 & 3.07 & $5.50 \times 10^{-6}$ \\
GO:0006956 complement activation & 8 & 3.07 & $1.24 \times 10^{-5}$ \\
GO:0072376 protein activation cascade & 8 & 3.07 & $1.65 \times 10^{-5}$ \\
GO:0006909 phagocytosis & 8 & 3.07 & $6.86 \times 10^{-5}$ \\
GO:0002455 humoral immune response mediated by circulating immunoglobulin & 8 & 3.07 & $3.11 \times 10^{-3}$ \\
\hline
\end{tabular}

Count: genes involved in the term; percentage (\%): involved genes/total genes; $p$-value: modified Fisher exact $p$-value.

Table 8. The functional analysis of the downregulated genes at $12 \mathrm{~h}$ after LLL irradiation.

\begin{tabular}{|c|c|c|c|}
\hline Gene Ontology (GO) ID and Terms on Biological Process (BP) & Count & $\%$ & $p$-Value \\
\hline GO:0034645 cellular macromolecule biosynthetic process & 102 & 23.83 & $6.82 \times 10^{-2}$ \\
\hline GO:0051171 regulation of nitrogen compound metabolic process & 94 & 21.96 & $2.85 \times 10^{-2}$ \\
\hline GO:0010556 regulation of macromolecule biosynthetic process & 90 & 21.03 & $1.75 \times 10^{-2}$ \\
\hline GO:0010468 regulation of gene expression & 90 & 21.03 & $6.33 \times 10^{-2}$ \\
\hline GO:0018130 heterocycle biosynthetic process & 90 & 21.03 & $8.55 \times 10^{-2}$ \\
\hline GO:0034654 nucleobase-containing compound biosynthetic process & 89 & 20.79 & $8.55 \times 10^{-2}$ \\
\hline GO:0019219 regulation of nucleobase-containing compound metabolic process & 88 & 20.56 & $3.19 \times 10^{-2}$ \\
\hline GO:2000112 regulation of cellular macromolecule biosynthetic process & 87 & 20.33 & $2.26 \times 10^{-2}$ \\
\hline GO:0097659 nucleic acid-templated transcription & 82 & 19.16 & $2.93 \times 10^{-2}$ \\
\hline GO:0032774 RNA biosynthetic process & 82 & 19.16 & $6.02 \times 10^{-2}$ \\
\hline GO:0051252 regulation of RNA metabolic process & 81 & 18.93 & $3.76 \times 10^{-2}$ \\
\hline GO:0006351 transcription, DNA-templated & 80 & 18.69 & $2.03 \times 10^{-2}$ \\
\hline GO:1903506 regulation of nucleic acid-templated transcription & 80 & 18.69 & $2.30 \times 10^{-2}$ \\
\hline GO:2001141 regulation of RNA biosynthetic process & 80 & 18.69 & $2.58 \times 10^{-2}$ \\
\hline GO:0006355 regulation of transcription, DNA-templated & 79 & 18.46 & $2.76 \times 10^{-2}$ \\
\hline GO:0023051 regulation of signaling & 77 & 17.99 & $1.04 \times 10^{-3}$ \\
\hline GO:0010646 regulation of cell communication & 76 & 17.76 & $1.04 \times 10^{-3}$ \\
\hline GO:0009966 regulation of signal transduction & 71 & 16.59 & $6.57 \times 10^{-4}$ \\
\hline GO:0065009 regulation of molecular function & 71 & 16.59 & $2.42 \times 10^{-3}$ \\
\hline GO:0035556 intracellular signal transduction & 69 & 16.12 & $8.62 \times 10^{-4}$ \\
\hline GO:0009893 positive regulation of metabolic process & 68 & 15.89 & $3.21 \times 10^{-2}$ \\
\hline GO:0010604 positive regulation of macromolecule metabolic process & 67 & 15.65 & $1.20 \times 10^{-2}$ \\
\hline GO:0006796 phosphate-containing compound metabolic process & 67 & 15.65 & $5.25 \times 10^{-2}$ \\
\hline GO:0006793 phosphorus metabolic process & 67 & 15.65 & $5.42 \times 10^{-2}$ \\
\hline GO:0031325 positive regulation of cellular metabolic process & 66 & 15.42 & $1.53 \times 10^{-2}$ \\
\hline GO:0044085 cellular component biogenesis & 65 & 15.19 & $3.58 \times 10^{-2}$ \\
\hline GO:0050790 regulation of catalytic activity & 63 & 14.72 & $7.74 \times 10^{-4}$ \\
\hline GO:0022607 cellular component assembly & 63 & 14.72 & $9.06 \times 10^{-3}$ \\
\hline GO:0007166 cell surface receptor signaling pathway & 59 & 13.79 & $5.38 \times 10^{-2}$ \\
\hline GO:0051128 regulation of cellular component organization & 57 & 13.32 & $9.42 \times 10^{-3}$ \\
\hline
\end{tabular}


Table 8. Cont.

\begin{tabular}{|c|c|c|c|}
\hline Gene Ontology (GO) ID and Terms on Biological Process (BP) & Count & $\%$ & $p$-Value \\
\hline GO:0016310 phosphorylation & 56 & 13.08 & $6.37 \times 10^{-3}$ \\
\hline GO:0051246 regulation of protein metabolic process & 55 & 12.85 & $7.26 \times 10^{-2}$ \\
\hline GO:0033554 cellular response to stress & 53 & 12.38 & $1.80 \times 10^{-4}$ \\
\hline GO:0007399 nervous system development & 52 & 12.15 & $2.06 \times 10^{-2}$ \\
\hline GO:0031324 negative regulation of cellular metabolic process & 52 & 12.15 & $6.82 \times 10^{-2}$ \\
\hline GO:0032268 regulation of cellular protein metabolic process & 51 & 11.92 & $9.24 \times 10^{-2}$ \\
\hline GO:1902531 regulation of intracellular signal transduction & 50 & 11.68 & $5.12 \times 10^{-4}$ \\
\hline GO:0044093 positive regulation of molecular function & 50 & 11.68 & $2.35 \times 10^{-3}$ \\
\hline GO:0006928 movement of cell or subcellular component & 48 & 11.21 & $4.02 \times 10^{-3}$ \\
\hline GO:0009605 response to external stimulus & 47 & 10.98 & $6.26 \times 10^{-2}$ \\
\hline GO:0043085 positive regulation of catalytic activity & 46 & 10.75 & $7.29 \times 10^{-4}$ \\
\hline GO:0007049 cell cycle & 46 & 10.75 & $2.94 \times 10^{-3}$ \\
\hline GO:0006357 regulation of transcription from RNA polymerase II promoter & 46 & 10.75 & $1.51 \times 10^{-2}$ \\
\hline GO:1902589 single-organism organelle organization & 45 & 10.51 & $2.52 \times 10^{-3}$ \\
\hline GO:0006366 transcription from RNA polymerase II promoter & 45 & 10.51 & $2.03 \times 10^{-2}$ \\
\hline GO:0008219 cell death & 44 & 10.28 & $8.02 \times 10^{-2}$ \\
\hline GO:0031399 regulation of protein modification process & 43 & 10.05 & $1.20 \times 10^{-2}$ \\
\hline GO:0048585 negative regulation of response to stimulus & 41 & 9.58 & $1.17 \times 10^{-3}$ \\
\hline GO:0007155 cell adhesion & 41 & 9.58 & $3.80 \times 10^{-2}$ \\
\hline GO:0022610 biological adhesion & 41 & 9.58 & $3.98 \times 10^{-2}$ \\
\hline
\end{tabular}

Count: genes involved in the term; percentage (\%): involved genes/total genes; $p$-value: modified Fisher exact $p$-value.

\subsection{PPI of Up- or Downregulated DEGs}

As for the upregulated DEGs, there were DEGs involved in the defense response at all irradiation times. From the functional analysis of DAVID, we focused on the defense response related to wound healing, which is the BP of the DEGs of the upregulated DEGs at 6 and $12 \mathrm{~h}$ after the irradiation. Among the genes involved in the defense response, HCP5, DAPK3, IGLC2 and IGHV1 OR21-1 at $1 \mathrm{~h}$ after the irradiation for the upregulated DEGs, HP, IGHE and TPSAB1 at $3 \mathrm{~h}$, CAKM2 B, IGHM, SEMA7 A, CXCL8 and TNFAIP6 at 6 h. IL34, ITGA2, SERPINE1, INHBA, PRDM1, LYZL4, PVR, BMP6, NFKB1, FOXP1, PER1, IGHG1, IGHA1, IGHA2, LDLR, SLC25 A6, PF4 and TGM2. At $12 \mathrm{~h}$, it was IGHM, ITIH4, SEMA7 A, EDN1, HIST1 H2 BJ, KCNJ8, TNFAIP6, CCL21, CARD9, IFI6, SERPINB9, LYZL2, DEFB108 B, ECSIT, IGHG1, IGKC, IGHD, CHRFAM7 A and SLAMF6.

As the results of PPI analysis of DEGs involved in the defense response with STRING, CXCL8 was a gene associated with multiple genes in the upregulated DEGs of the defense response. The relationships with SERPINE1, PF4, NFKB1, TNFAIP6, EDN1, CCL21, ITIH4 and HP were confirmed. In addition, HP, ITIH4, TNFAIP6 and NFKB1 were also associated with multiple genes (Figure 1). In the downregulated DEGs, STAT1 was a gene associated with multiple genes. In particular, it was associated with SMAD3, IL15, CCL22, NAIP, NRIH3, LY96, NFKBIA, PSMB8, PSMB9, PSMB10, OSA2, OAS3, IRF2, BCL6 and DDX58. In addition, NFKBIA, TLR3, IL15 and IRF2 were genes associated with multiple genes (Figure 2).

Figure 3 shows the changes in the expression of major genes related to other genes over time. 


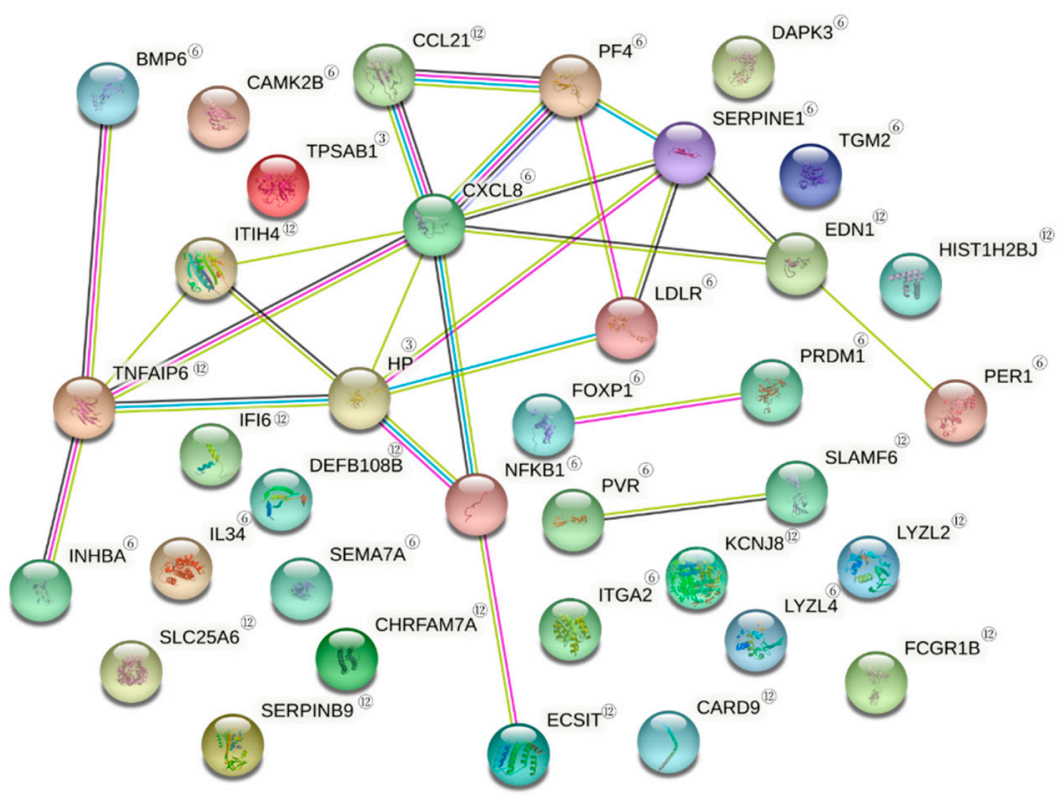

Figure 1. PPI of upregulated DEGs. Search tool STRING analysis of interacting genes and proteins reveals a protein-protein interaction PPI network in defense response by LLLT. PPI of upregulated DEGs related to 'defense response' Related genes after the irradiation at $3 \mathrm{~h}$; (3), $6 \mathrm{~h}$; (6) $12 \mathrm{~h}$; (12) Red line: indicates the presence of fusion evidence; green line: neighborhood evidence; blue line: cooccurrence evidence; purple line: experimental evidence; yellow line: text mining evidence; light blue line: database evidence; black line: coexpression evidence.

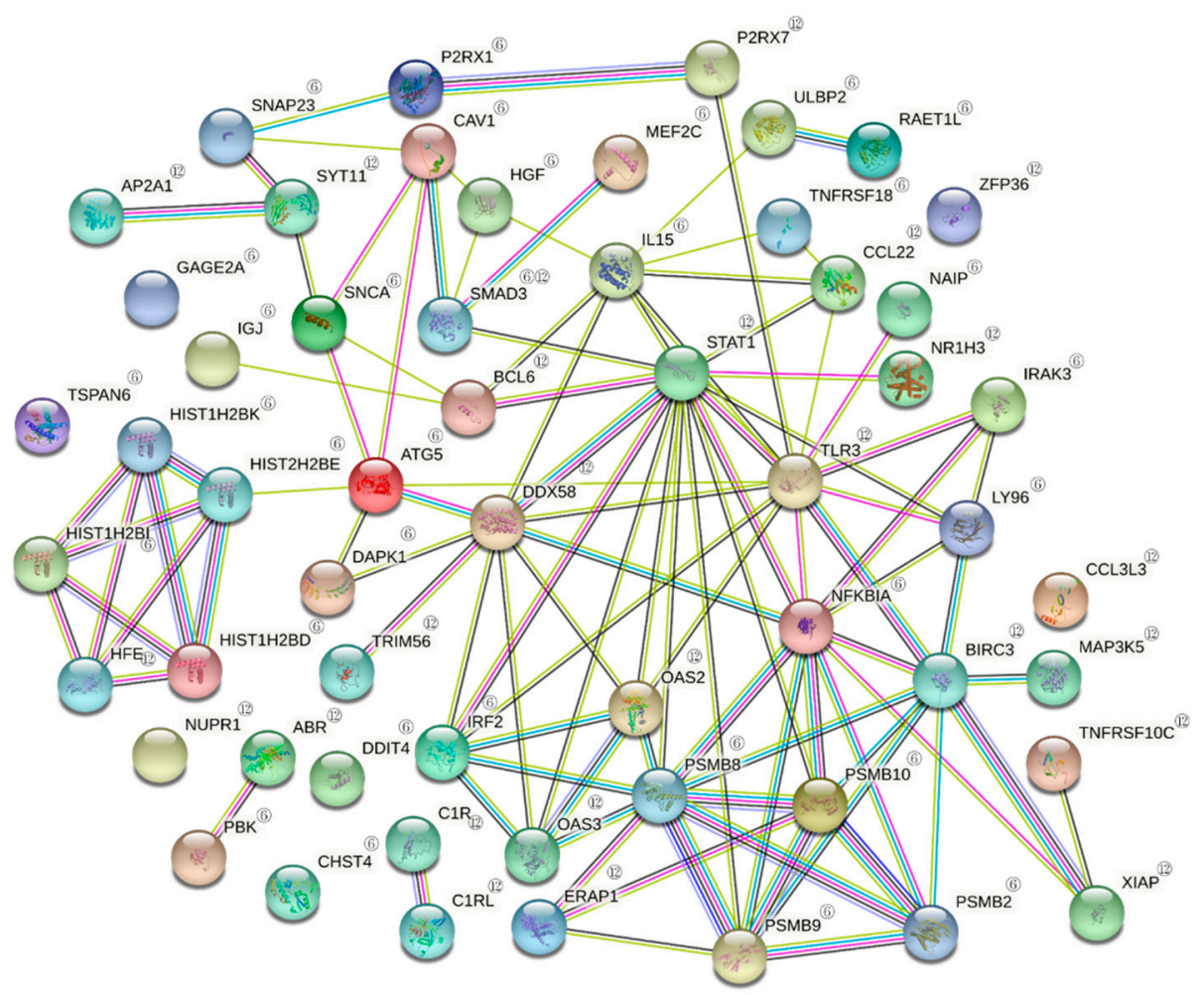

Figure 2. PPI of downregulated DEGs. Search tool STRING analysis of interacting genes and proteins reveals a protein-protein interaction network between proteins in defense response by LLLT. PPI of downregulated DEGs related to 'defense response.' Related genes after the irradiation at $3 \mathrm{~h}$; (3) , 6 h; (6) $12 \mathrm{~h}$; (12). 
$3 \mathrm{~h}$

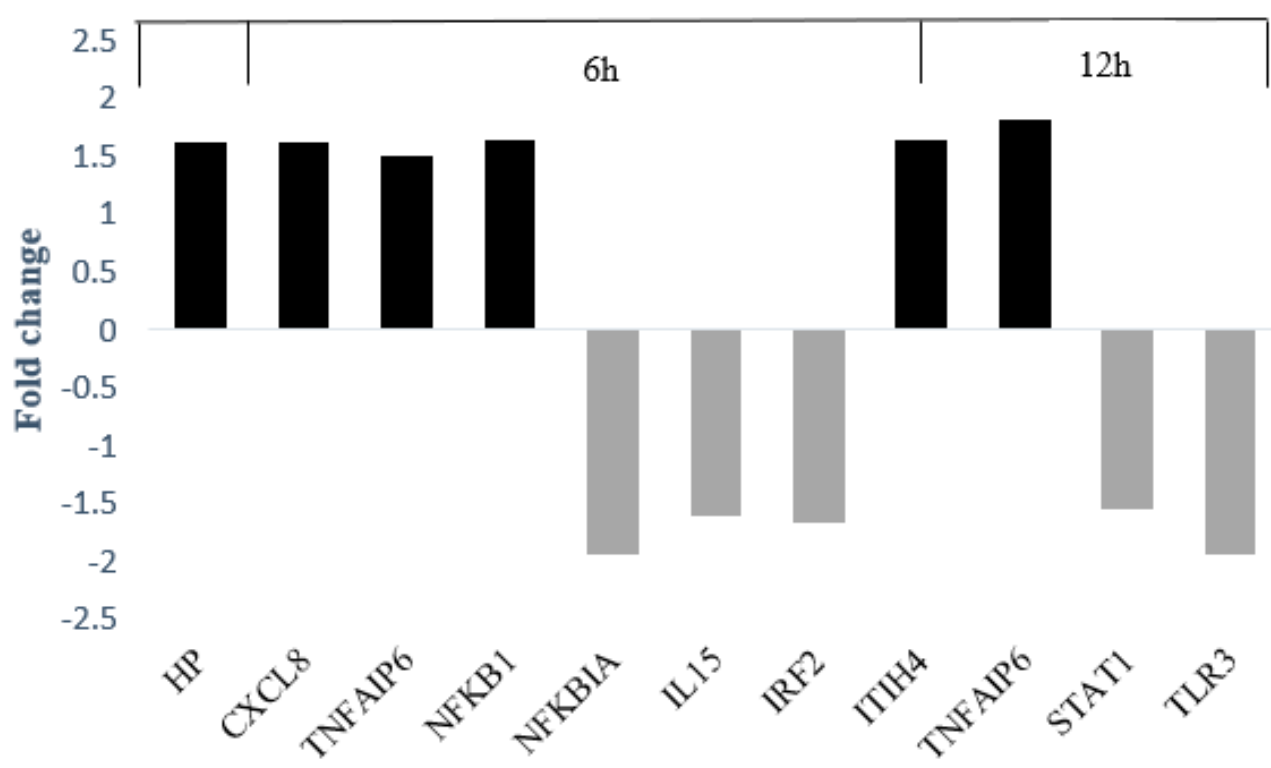

Figure 3. The FC of the key genes.

\section{Discussion}

Laser treatment has been studied for clinical application in many fields including medical and dentistry. In the field of dentistry, lasers are used for various purposes such as promoting wound healing, gingival incision, caries removal and sterilization/disinfection effect [25]. It has been reported that LLLT promotes wound healing and bone formation in the oral cavity by utilizing the bioactivating effect of chronic periodontitis.

In addition, at the cellular and tissue levels, there are research reports related to promotion of wound healing, such as cell proliferation of fibroblasts [15,20], osteoblasts [22,26] and vascular endothelial cells $[18,27]$ by LLLT. However, clinical application in medical and dental treatments has not been carried out much. This is because the molecular biological findings are not clear.

Intracellular biological effects of LLLT include physiological activity by photoreceptors, changes in intracellular signal cascades, and changes in genes. The intracellular photoreceptor of LLLT is cytochrome c oxidase, which is a transmembrane protein complex that is an electron transport chain enzyme found in mitochondria. Promotion of cell proliferation by increasing cytochrome c oxidase activity and ATP is one of the representative mechanisms in LLLT research [28-31].

As a method for elucidating the mechanism of wound healing by LLLT, DNA microarrays are considered to be useful because they can examine thousands to tens of thousands of gene expressions at a time. From the obtained gene expression data, DEGs are extracted using bioinformatics analysis tools [32,33]. Furthermore, based on GO, by analyzing the biological process (BP) of DEGs, it is possible to estimate what is happening at each time by knowing the known functions of the gene contained in DEGs. It is also possible to infer what is about to happen at that time by performing chronological analysis. In addition, by searching for protein-protein interaction (PPI), it is possible to search for relationships at the molecular level $[34,35]$. The method plays a major role in elucidating the effects of proteins controlled by LLLT-stimulated genes at the molecular level.

In this study, we focused on the defense response from a huge amount of microarray data and analyzed the chronological changes in gene expression and the function of the genes after LLLT to HGF and the function of the genes.

The gene expression reactions related to wound healing with LLLT were remarkable 6-12 $\mathrm{h}$ after the irradiation. Analysis of the gene expression changes within these times were considered important for investigating the molecular mechanism of effects on HGF 
with LLLT. In particular, among the DEGs, those that are common over time and those with a significantly large expression fluctuation amount were considered largely affected by LLLT.

Analysis of BP over time revealed that upregulated were activated from 1 to $3 \mathrm{~h}$ after the initial irradiation, and downregulated BP was involved in RNA metabolism and activity. In both cases, the number of applicable DEGs for BP was 10 or less. It was suggested that there was no cohesive expression fluctuation as a function.

At $6 \mathrm{~h}$ after the irradiation, upregulated DEGs were observed related to cell proliferation, adhesion and defense reaction. Additionally, downregulated DEGs were observed in many BPs involved in RNA metabolism, activity, cell polymer production, and metabolism.

At $12 \mathrm{~h}$ after the irradiation, upregulated DEGs were observed with many BPs involved in defense reaction, immune reaction and response to external stimuli, and downregulated DEGs were observed with many BPs involved in RNA metabolism, activity, cell polymer production and metabolism. In the upregulated group, many BPs associated with wound healing were observed at 6-12 h after irradiation. Additionally, in downregulated, similar $\mathrm{BP}$ such as RNA metabolism were observed from 1 to $12 \mathrm{~h}$ after irradiation.

The BP 'the defense response' focused on in this study belongs to the BP 'the response to stress of response to stimulus' in GO. The response to stimulus is the process by which the state or activity of a cell or organism changes as a result of stimulation. The response to stress also causes motility, secretion, enzyme production, gene expression, etc., as a result of impaired homeostasis of the organism or cell due to extrinsic factors (temperature, humidity, ionizing radiation). The defense response, which belongs to response to stress, is a reaction caused in response to the presence of foreign substances or the occurrence of injuries, and is an important BP involved in the restriction, prevention/recovery of damage to living organisms.

In the BP 'defense response', the protein encoded by CXCL8, which is a downregulated DEG, is called interleukin-8 (IL-8). IL-8 is secreted by mononuclear macrophages, neutrophils, eosinophils, T lymphocytes, epithelial cells, and fibroblasts. IL-8 is also known as a neutrophil chemotactic factor with two major functions. It induces chemotaxis of target cells to the infected site. IL-8 is also known as a strong promoter of angiogenesis. IL-8 expression is regulated by the transcription factor NF- $\mathrm{kB}$ [36-42].

In particular, the upregulated DEGs NFKB1 and the downregulated DEGs NFKBIA are genes involved in NF- $\mathrm{KB}$. These are one of the genes involved in the existing mechanism. NFKB1 is a transcriptional regulator that is activated by various intracellular and extracellular stimuli such as cytokines, oxidant free radicals, UV irradiation and bacterial or viral products. Activated NFKB stimulates the expression of genes involved in biological functions associated with many biological processes such as inflammation, immunity, differentiation and cells [43]. NFKBIA is a member of a family of cellular proteins that function to inhibit NF- $\kappa B$ transcription factors and I $\kappa \mathrm{B} \alpha$ masks the nuclear localization signals (NLS) of NF- $\mathrm{kB}$ proteins and inactivates them in the cytoplasm. It inhibits NF- $\mathrm{kB}$ by isolating it into a state [44]. From this result, it can be seen that NFKB1 increases and NFKBIA decreases when irradiation is performed, so that the activity of the pathway containing NF- $\mathrm{KB}$ occurs. Additionally, the defense response of BP is considered to be strongly related to the NF- $\mathrm{KB}$ pathway.

In a study by Chen et al., NF- $\mathrm{kB}$ activity was observed $1-10 \mathrm{~h}$ after irradiation [21].

In this study as well, changes in the expression of NFKB1 and NFKBIA were observed $6 \mathrm{~h}$ after irradiation, and the results of analysis from the viewpoint of BP also suggest that the movement of NF- $\mathrm{kB}$ due to irradiation is an important process in the mechanism of LLLT. In this study, we focused on the defense response. Further, we also will need to focus on wound healing-related processes such as $\mathrm{BP}$ 'the immune response'.

By adding analysis more time points, it is possible to analyze detailed time-series processes after LLL irradiation. As future developments, we plan to study other BPs, collect LLLT microarray data at different time points, and analyze the effects of laser irradiation on fibroblasts and molecular-level processes during the healing process. We will lead to 
the elucidation of molecular evidence in 'the response to stress of response to stimulus' by LLLT.

\section{Conclusions}

The time points of 1, 3, 6 and $12 \mathrm{~h}$ after LLL irradiation were compared over time. The most DEGs after the LLL irradiation on HGF were showed at $6 \mathrm{~h}$ upregulated gene. The number of DEGs peaked $6 \mathrm{~h}$ after irradiation and slightly decreased at $12 \mathrm{~h}$ after irradiation. From the time-dependent functional analysis, the upregulated DEGs were involved in BPs of cell proliferation, adhesion, and defense response related to wound healing from $6 \mathrm{~h}$. In addition, defense response is one of the important mechanisms in BP after the irradiation. We found that the upregulated DEGs such as CXCL8 and NFKB1, and the downregulated DEGs such as NFKBIA and STAT1 were correlated with multiple genes from these PPI. From these results, irradiation of LLLT showed fluctuations in the expression of genes related to $\mathrm{BP}$ defense response.

Supplementary Materials: The following are available online at https:/ /www.mdpi.com/article/10 $.3390 / \mathrm{jcm} 10091952 / \mathrm{s} 1$, Table S1: DEGs of the up-regulated genes at $1 \mathrm{~h}$ after LLL irradiation, Table S2: DEGs of the down-regulated genes at $1 \mathrm{~h}$ after LLL irradiation, Table S3: DEGs of the up-regulated genes at $3 \mathrm{~h}$ after LLL irradiation, Table S4: DEGs of the down-regulated genes at $3 \mathrm{~h}$ after LLL irradiation, Table S5: DEGs of the up-regulated genes at $6 \mathrm{~h}$ after LLL irradiation, Table S6: DEGs of the down-regulated genes at $6 \mathrm{~h}$ after LLL irradiation, Table S7: DEGs of the up-regulated genes at $12 \mathrm{~h}$ after LLL irradiation, Table S8: DEGs of the down-regulated genes at $12 \mathrm{~h}$ after LLL irradiation.

Author Contributions: Conceptualization, Y.W., A.S., H.I., E.M. and Y.N.; methodology, Y.W., A.S., H.I., E.M. and E.M.; software, Y.W. and A.S.; validation, Y.W., A.S., H.I., and E.M.; formal analysis, Y.W., A.S. and H.I.; investigation, Y.W., A.S., H.I., and E.M.; resources, Y.W., A.S., H.I., and E.M.; data curation, Y.W., A.S., H.I., and E.M.; writing—original draft preparation, Y.W., A.S., H.I., E.M. and Y.N.; writing-review and editing, Y.W., A.S., H.I., E.M. and Y.N.; visualization, Y.W. and A.S.; supervision, Y.N.; project administration, A.S., H.I., and E.M.; funding acquisition, H.I. and E.M. All authors have read and agreed to the published version of the manuscript.

Funding: This research was funded by grants from the JSPS KAKENHI (grant numbers: JP18 K09585).

Institutional Review Board Statement: Not applicable.

Informed Consent Statement: Not applicable.

Conflicts of Interest: The authors declare no conflict of interest.

\section{References}

1. Lopes, B.M.V.; Marcantonio, R.A.C.; Thompson, G.M.A.; Neves, L.H.M.; Theodoro, L.H. Short-Term Clinical and Immunologic Effects of Scaling and Root Planing With Er:YAG Laser in Chronic Periodontitis. J. Periodontol. 2008, 79, 1158-1167. [CrossRef] [PubMed]

2. Schwarz, F.; Sculean, A.; Georg, T.; Reich, E. Periodontal Treatment With an Er:YAG Laser Compared to Scaling and Root Planing. A Controlled Clinical Study. J. Periodontol. 2001, 72, 361-367. [CrossRef]

3. Crespi, R.; Capparè, P.; Toscanelli, I.; Gherlone, E.; Romanos, G.E. Effects of Er:YAG Laser Compared to Ultrasonic Scaler in Periodontal Treatment: A 2-Year Follow-Up Split-Mouth Clinical Study. J. Periodontol. 2007, 78, 1195-1200. [CrossRef]

4. White, J.M.; Goodis, H.E.; Rose, C.L. Use of the Pulsed Nd:YAG Laser for Intraoral Soft Tissue Surgery. Lasers Surg. Med. 1991, 11, 455-461. [CrossRef]

5. Lauritano, D.; Lucchese, A.; Gabrione, F.; Di Stasio, D.; Silvestre Rangil, J.; Carinci, F. The Effectiveness of Laser-Assisted Surgical Excision of Leukoplakias and Hyperkeratosis of Oral Mucosa: A Case Series in A Group of Patients. Int. J. Environ. Res. Public. Health 2019, 16, 210. [CrossRef]

6. Pick, R.M.; Colvard, M.D. Current Status of Lasers in Soft Tissue Dental Surgery. J. Periodontol. 1993, 64, 589-602. [CrossRef]

7. Aimbire, F.; Santos, F.V.; Albertini, R.; Castro-Faria-Neto, H.C.; Mittmann, J.; Pacheco-Soares, C. Low-Level Laser Therapy Decreases Levels of Lung Neutrophils Anti-Apoptotic Factors by a NF-KappaB Dependent Mechanism. Int. Immunopharmacol. 2008, 8, 603-605. [CrossRef]

8. Aimbire, F.; Ligeiro de Oliveira, A.P.; Albertini, R.; Corrêa, J.C.; Ladeira de Campos, C.B.; Lyon, J.P.; Silva, J.A.; Costa, M.S. Low Level Laser Therapy (LLLT) Decreases Pulmonary Microvascular Leakage, Neutrophil Influx and IL-1beta Levels in Airway and Lung from Rat Subjected to LPS-Induced Inflammation. Inflammation 2008, 31, 189-197. [CrossRef] 
9. Albertini, R.; Aimbire, F.S.C.; Correa, F.I.; Ribeiro, W.; Cogo, J.C.; Antunes, E.; Teixeira, S.A.; De Nucci, G.; Castro-Faria-Neto, H.C.; Zângaro, R.A.; et al. Effects of Different Protocol Doses of Low Power Gallium-Aluminum-Arsenate (Ga-Al-As) Laser Radiation $(650 \mathrm{Nm})$ on Carrageenan Induced Rat Paw Ooedema. J. Photochem. Photobiol. B 2004, 74, 101-107. [CrossRef] [PubMed]

10. Albertini, R.; Villaverde, A.B.; Aimbire, F.; Bjordal, J.; Brugnera, A.; Mittmann, J.; Silva, J.A.; Costa, M. Cytokine MRNA Expression Is Decreased in the Subplantar Muscle of Rat Paw Subjected to Carrageenan-Induced Inflammation after Low-Level Laser Therapy. Photomed. Laser Surg. 2008, 26, 19-24. [CrossRef] [PubMed]

11. Albertini, R.; Aimbire, F.; Villaverde, A.B.; Silva, J.A.; Costa, M.S. COX-2 MRNA Expression Decreases in the Subplantar Muscle of Rat Paw Subjected to Carrageenan-Induced Inflammation after Low Level Laser Therapy. Inflamm. Res. Off. J. Eur. Histamine Res. Soc. Al 2007, 56, 228-229. [CrossRef]

12. Albertini, R.; Villaverde, A.B.; Aimbire, F.; Salgado, M.A.C.; Bjordal, J.M.; Alves, L.P.; Munin, E.; Costa, M.S. Anti-Inflammatory Effects of Low-Level Laser Therapy (LLLT) with Two Different Red Wavelengths (660 Nm and $684 \mathrm{Nm}$ ) in Carrageenan-Induced Rat Paw Edema. J. Photochem. Photobiol. B 2007, 89, 50-55. [CrossRef] [PubMed]

13. Aoki, A.; Mizutani, K.; Schwarz, F.; Sculean, A.; Yukna, R.A.; Takasaki, A.A.; Romanos, G.E.; Taniguchi, Y.; Sasaki, K.M.; Zeredo, J.L.; et al. Periodontal and Peri-Implant Wound Healing Following Laser Therapy. Periodontol. 2000 2015, 68, 217-269. [CrossRef] [PubMed]

14. Kami, T.; Yoshimura, Y.; Nakajima, T.; Ohshiro, T.; Fujino, T. Effects of Low-Power Diode Lasers on Flap Survival. Ann. Plast. Surg. 1985, 14, 278-283. [CrossRef]

15. Ogita, M.; Tsuchida, S.; Aoki, A.; Satoh, M.; Kado, S.; Sawabe, M.; Nanbara, H.; Kobayashi, H.; Takeuchi, Y.; Mizutani, K.; et al. Increased Cell Proliferation and Differential Protein Expression Induced by Low-Level Er:YAG Laser Irradiation in Human Gingival Fibroblasts: Proteomic Analysis. Lasers Med. Sci. 2015, 30, 1855-1866. [CrossRef] [PubMed]

16. Kipshidze, N.; Nikolaychik, V.; Keelan, M.H.; Shankar, L.R.; Khanna, A.; Kornowski, R.; Leon, M.; Moses, J. Low-Power Helium Neon Laser Irradiation Enhances Production of Vascular Endothelial Growth Factor and Promotes Growth of Endothelial Cells in Vitro. Lasers Surg. Med. 2001, 28, 355-364. [CrossRef] [PubMed]

17. Yu, H.S.; Chang, K.L.; Yu, C.L.; Chen, J.W.; Chen, G.S. Low-Energy Helium-Neon Laser Irradiation Stimulates Interleukin-1 Alpha and Interleukin-8 Release from Cultured Human Keratinocytes. J. Investig. Dermatol. 1996, 107, 593-596. [CrossRef]

18. Khanna, A.; Shankar, L.R.; Keelan, M.H.; Kornowski, R.; Leon, M.; Moses, J.; Kipshidze, N. Augmentation of the Expression of Proangiogenic Genes in Cardiomyocytes with Low Dose Laser Irradiation in Vitro. Cardiovasc. Radiat. Med. 1999, 1, 265-269. [CrossRef]

19. Gkogkos, A.S.; Karoussis, I.K.; Prevezanos, I.D.; Marcopoulou, K.E.; Kyriakidou, K.; Vrotsos, I.A. Effect of Nd:YAG Low Level Laser Therapy on Human Gingival Fibroblasts. Int. J. Dent. 2015, 2015. [CrossRef]

20. Misa, O.; Etsuko, M.; Hitomi, I.; Hiroko, T.-I.; Yukihiro, N. Effect of Low-Level Nd: YAG Laser Irradiation for Wound Healing on Human Gingival Fibroblasts. Ph.D. Thesis, The Nippon Dental University, Tokyo, Japan, 2016.

21. Chen, A.C.-H.; Arany, P.R.; Huang, Y.-Y.; Tomkinson, E.M.; Sharma, S.K.; Kharkwal, G.B.; Saleem, T.; Mooney, D.; Yull, F.E.; Blackwell, T.S.; et al. Low-Level Laser Therapy Activates NF-KB via Generation of Reactive Oxygen Species in Mouse Embryonic Fibroblasts. PLoS ONE 2011, 6, e22453. [CrossRef]

22. Ohsugi, Y.; Aoki, A.; Mizutani, K.; Katagiri, S.; Komaki, M.; Noda, M.; Takagi, T.; Kakizaki, S.; Meinzer, W.; Izumi, Y. Evaluation of Bone Healing Following Er:YAG Laser Ablation in Rat Calvaria Compared with Bur Drilling. J. Biophotonics 2019, 12, e201800245. [CrossRef] [PubMed]

23. Kong, S.; Aoki, A.; Iwasaki, K.; Mizutani, K.; Katagiri, S.; Suda, T.; Ichinose, S.; Ogita, M.; Pavlic, V.; Izumi, Y. Biological Effects of Er:YAG Laser Irradiation on the Proliferation of Primary Human Gingival Fibroblasts. J. Biophotonics 2018, 11. [CrossRef] [PubMed]

24. Naoya, Y.; Etsuko, M.; Hiroko, I.; Yukihiro, N. The Effect of Nd:YAG Laser Irradiation on Human Gingival Fibroblasts-A Study of the Irradiation Output and Distance. J. Jpn. Soc. Laser Dent. 2013, 24, 72-82. (In Japanese) [CrossRef]

25. Akiyama, F.; Aoki, A.; Miura-Uchiyama, M.; Sasaki, K.M.; Ichinose, S.; Umeda, M.; Ishikawa, I.; Izumi, Y. In Vitro Studies of the Ablation Mechanism of Periodontopathic Bacteria and Decontamination Effect on Periodontally Diseased Root Surfaces by Erbium:Yttrium-Aluminum-Garnet Laser. Lasers Med. Sci. 2011, 26, 193-204. [CrossRef]

26. Pyo, S.-J.; Song, W.-W.; Kim, I.-R.; Park, B.-S.; Kim, C.-H.; Shin, S.-H.; Chung, I.-K.; Kim, Y.-D. Low-Level Laser Therapy Induces the Expressions of BMP-2, Osteocalcin, and TGF-B1 in Hypoxic-Cultured Human Osteoblasts. Lasers Med. Sci. 2013, 28, 543-550. [CrossRef] [PubMed]

27. Li, Y.; Xu, Q.; Shi, M.; Gan, P.; Huang, Q.; Wang, A.; Tan, G.; Fang, Y.; Liao, H. Low-Level Laser Therapy Induces Human Umbilical Vascular Endothelial Cell Proliferation, Migration and Tube Formation through Activating the PI3K/Akt Signaling Pathway. Microvasc. Res. 2020, 129, 103959. [CrossRef]

28. Karu, T.I.; Pyatibrat, L.V.; Afanasyeva, N.I. Cellular Effects of Low Power Laser Therapy Can Be Mediated by Nitric Oxide. Lasers Surg. Med. 2005, 36, 307-314. [CrossRef] [PubMed]

29. Smith, K.C. The Photobiological Basis of Low Level Laser Radiation Therapy. Laser Ther. 1991, 3, 19-24. [CrossRef]

30. Silveira, P.C.L.; Streck, E.L.; Pinho, R.A. Evaluation of Mitochondrial Respiratory Chain Activity in Wound Healing by Low-Level Laser Therapy. J. Photochem. Photobiol. B Biol. 2007, 86, 279-282. [CrossRef]

31. Lim, J.; Sanders, R.A.; Snyder, A.C.; Eells, J.T.; Henshel, D.S.; Watkins, J.B. Effects of Low-Level Light Therapy on StreptozotocinInduced Diabetic Kidney. J. Photochem. Photobiol. B Biol. 2010, 99, 105-110. [CrossRef] 
32. Huang, D.W.; Sherman, B.T.; Lempicki, R.A. Bioinformatics Enrichment Tools: Paths toward the Comprehensive Functional Analysis of Large Gene Lists. Nucleic Acids Res. 2009, 37, 1-13. [CrossRef] [PubMed]

33. Huang, D.W.; Sherman, B.T.; Lempicki, R.A. Systematic and Integrative Analysis of Large Gene Lists Using DAVID Bioinformatics Resources. Nat. Protoc. 2009, 4, 44-57. [CrossRef] [PubMed]

34. Zeidán-Chuliá, F.; Gursoy, M.; de Oliveira, B.-H.N.; Gelain, D.P.; Könönen, E.; Gursoy, U.K.; Moreira, J.C.F.; Uitto, V.-J. Focussed Microarray Analysis of Apoptosis in Periodontitis and Its Potential Pharmacological Targeting by Carvacrol. Arch. Oral Biol. 2014, 59, 461-469. [CrossRef]

35. Zeidán-Chuliá, F.; Rybarczyk-Filho, J.L.; Gursoy, M.; Könönen, E.; Uitto, V.-J.; Gursoy, O.V.; Cakmakci, L.; Moreira, J.C.F.; Gursoy, U.K. Bioinformatical and in Vitro Approaches to Essential Oil-Induced Matrix Metalloproteinase Inhibition. Pharm. Biol. 2012, 50, 675-686. [CrossRef]

36. Van Damme, J.; Rampart, M.; Conings, R.; Decock, B.; Van Osselaer, N.; Willems, J.; Billiau, A. The Neutrophil-Activating Proteins Interleukin 8 and Beta-Thromboglobulin: In Vitro and in Vivo Comparison of NH2-Terminally Processed Forms. Eur. J. Immunol. 1990, 20, 2113-2118. [CrossRef]

37. Schutyser, E.; Struyf, S.; Proost, P.; Opdenakker, G.; Laureys, G.; Verhasselt, B.; Peperstraete, L.; Van de Putte, I.; Saccani, A.; Allavena, P.; et al. Identification of Biologically Active Chemokine Isoforms from Ascitic Fluid and Elevated Levels of CCL18/Pulmonary and Activation-Regulated Chemokine in Ovarian Carcinoma. J. Biol. Chem. 2002, 277, 24584-24593. [CrossRef] [PubMed]

38. Hébert, C.A.; Luscinskas, F.W.; Kiely, J.M.; Luis, E.A.; Darbonne, W.C.; Bennett, G.L.; Liu, C.C.; Obin, M.S.; Gimbrone, M.A.; Baker, J.B. Endothelial and Leukocyte Forms of IL-8. Conversion by Thrombin and Interactions with Neutrophils. J. Immunol. 1990, 145, 3033-3040.

39. Ungureanu, D.; Vanhatupa, S.; Kotaja, N.; Yang, J.; Aittomaki, S.; Jänne, O.A.; Palvimo, J.J.; Silvennoinen, O. PIAS Proteins Promote SUMO-1 Conjugation to STAT1. Blood 2003, 102, 3311-3313. [CrossRef]

40. Zhang, Y.; Mao, D.; Roswit, W.T.; Jin, X.; Patel, A.C.; Patel, D.A.; Agapov, E.; Wang, Z.; Tidwell, R.M.; Atkinson, J.J.; et al. PARP9-DTX3L Ubiquitin Ligase Targets Host Histone H2BJ and Viral 3C Protease to Enhance Interferon Signaling and Control Viral Infection. Nat. Immunol. 2015, 16, 1215-1227. [CrossRef]

41. Chen, K.; Liu, J.; Liu, S.; Xia, M.; Zhang, X.; Han, D.; Jiang, Y.; Wang, C.; Cao, X. Methyltransferase SETD2-Mediated Methylation of STAT1 Is Critical for Interferon Antiviral Activity. Cell 2017, 170, 492-506.e14. [CrossRef]

42. Liu, B.; Liao, J.; Rao, X.; Kushner, S.A.; Chung, C.D.; Chang, D.D.; Shuai, K. Inhibition of Stat1-Mediated Gene Activation by PIAS1. Proc. Natl. Acad. Sci. USA 1998, 95, 10626-10631. [CrossRef] [PubMed]

43. Beinke, S.; Robinson, M.J.; Hugunin, M.; Ley, S.C. Lipopolysaccharide Activation of the TPL-2/MEK/Extracellular SignalRegulated Kinase Mitogen-Activated Protein Kinase Cascade Is Regulated by IkappaB Kinase-Induced Proteolysis of NF-KappaB1 P105. Mol. Cell. Biol. 2004, 24, 9658-9667. [CrossRef] [PubMed]

44. Scherer, D.C.; Brockman, J.A.; Chen, Z.; Maniatis, T.; Ballard, D.W. Signal-Induced Degradation of I Kappa B Alpha Requires Site-Specific Ubiquitination. Proc. Natl. Acad. Sci. USA 1995, 92, 11259-11263. [CrossRef] [PubMed] 